\title{
THE PHYLOGENETIC SIGNIFICANCE OF THE PLANTAR RESPONSE IN MAN.
}

\author{
BY G. DF M. RUDOLF, Loxdox. \\ I.-INTRODUCTION.
}

TuE significance of the Babinski reflex, or the extensor plantar. response, has been rery much discussed. Many theories have been formulated, some dealing with the phylogenetic side of the question, others with the physiological. One of the hypotheses based upon phylogenetic considerations states that the extensor plantar response signifies a reversion to the prehensile functions of the great toe of our arboreal ancestors. ${ }^{7}, 17$ This is the theory most generally held by the supporters of the phylogenetic significance of the plantar response.

Physiologically, the normai adult flexor plantar response is generally held to be dependent upon the integrity of the crossed pyramidal tracts, and does not appear until myelination of the pyramidal fibres occurs. Both the normal infantile and the pathological extensor responses are believed to be parts of a defensive reflex, Sherrington's nociceptive flexion reflex of the whole limb.

With the object of endeavouring to determine what are the underlying fundamental principles of the plantar response, certain investigations, described below, were undertaken. These consisted of the examination of one part only of the plantar response, the movement of the great toe, in some of the lower animals and in British-born infants up to fourteen days old. In both classes the subjects examined were apparently healthy.

Although, in these investigations, the movement of the great toe was the only response studied, it must not be forgotten that this is but one part of the plantar response, for the entire reflex consists of movements of the whole limb and sometimes of the limb which is not stimulated as well. As, however, the movement of the great toe is that portion of the plantar response which is most used in clinical medicine, it is the most important part, from a practical standpoint, of the reflex.

The stimulation employed to invoke the response was effected by stroking the plantar surface of the foot from the heel in an anterior direction, using a pointed pencil, the finger-nail, or a pin. In the 
case of one animal, the chimpanzee, stimuli of different strengths were used in order to discover whether the type of response varies with the pressure employed. The stimuli were produced by the use of strong and light pressure with the end of a pencil, and strong and light pressure with a straw. In each case an extensor response was obtained. This was, however, more marked with the heavier pressures, although it was quite definite with the lighter. As the chimpanzee has a thick layer of skin upon the sole of its foot, it appears that the thickness of the skin, and therefore the pressure employed, does not affect the nature of the response, but only the degree. This corresponds with the findings of Riddoch in complete transection of the cord in man, ${ }^{12}$ for he noted that the greater the stimulus employed the greater was the response-up to a certain limit, of course.

If, however, the pressure used is very great and the stimulus is applied in the middle or medial part of the sole, a flexor plantar response is obtained, due to the pressure upon the plantar muscles approximating the central and distal ends of these structures and thus bending the toe downward. That this flexor movement of the great toe obtained with heavy pressure is not a true reflex action can be realized from the following experiment.

The plantar reflexes were examined in a man of about 25 years of age, fifteen minutes after death. The subject had apparently been healthy at the time of the accident. He had been riding a bicycle and his machine skidded; the wheel of a motor omnibus passed over his head, killing him instantaneously. It was found that when the sole of the foot was stimulated with light pressure no response of any description was obtained. On using heavier pressure, however, towards the medial part of the foot, the great toe flexed. This flexion was more gradual than that of a flexor plantar response, and it increased as the stimulating point approached the toe; thus clearly showing that a movement of plantar flexion of the great toe can be obtained, even in the absence of all reflex response, if sufficiently strong stimuli are employed.

In all the investigations the plantar response was taken to be the first movement of the great toe after the stimulus had been applied. Succeeding movements were not noted, as they are, in the majority of cases, of a voluntary nature. In some instances, however, it was very difficult to differentiate between a plantar flexion response and a dorsiflexion, or extension, movement, on account of the occurrence of voluntary movements. In the case of animals there was the added voluntary movement of grasping, which does not apparently occur to the same extent in the human baby. Sometimes it became necessary to hold the legs while the stimulus was being applied. 


\section{II.-THE PLANTAR RESPONSE OF THE LOWER ANIMAL.}

The following table shows the results obtained upon the animals examined.

Table $I$.

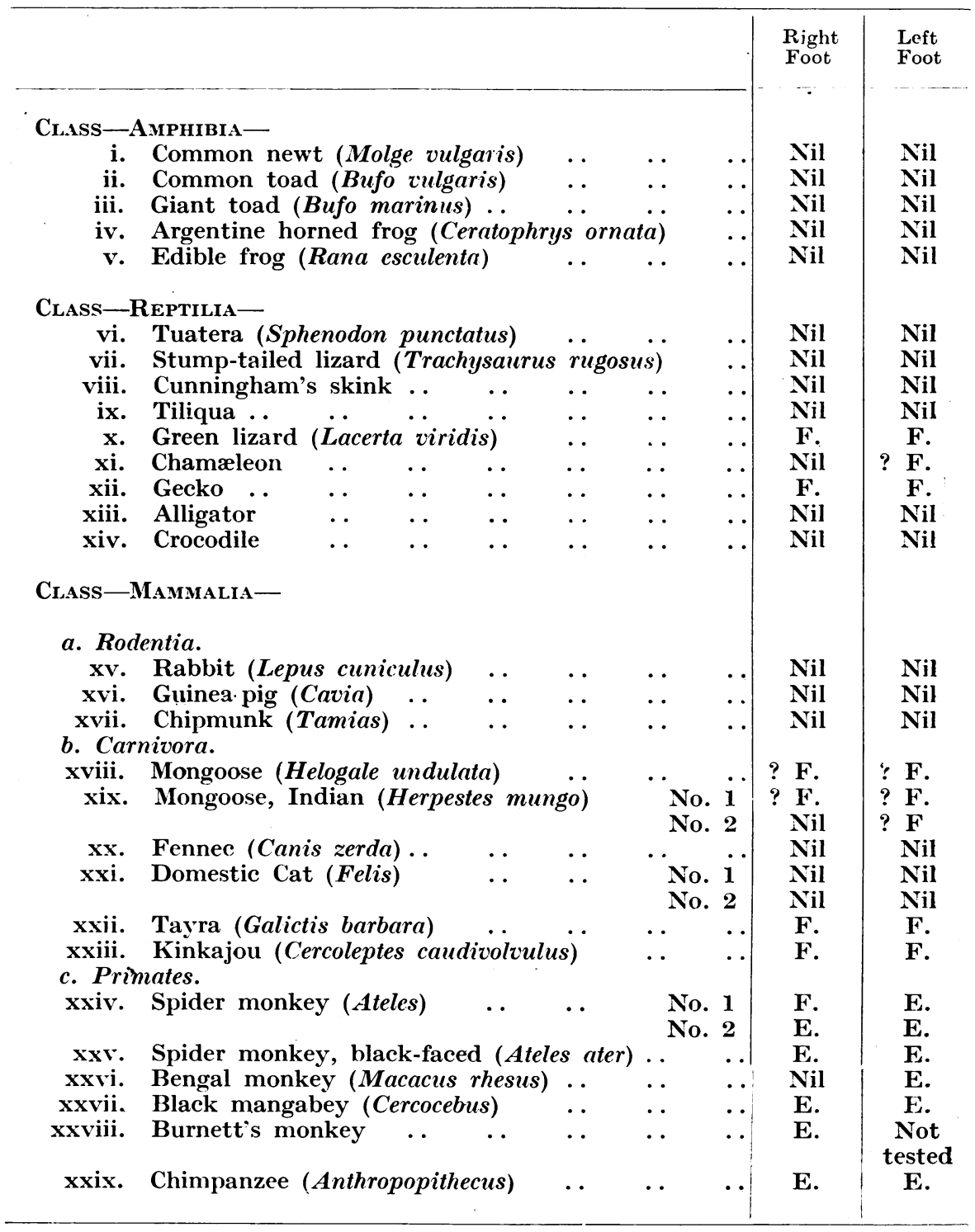

$[$ Note - Nil $=$ No response obtained. $\quad$ E. $=$ Extensor or dorsiflexion F. = Flexor or plantar flexion.] 
Upon consideration of the above table, it will be seen that amongst the lower classes of the animal kingdom the plantar response is either absent or is flexor in type. No response at all was obtained in the amphibia, and amongst the reptilia only three creatures, the chamæleon, the gecko, and the green lizard, gave responses, in each case flexor in character. There is doubt whether the response was present in the chamæleon, although, if so, it was flexor. The absence of certainty in regard to the reflex in this creature is due to the nature of its feet ; the toes are divided into two parts, three of them being united by a web and forming the outer half of the foot, the remaining two being also united and forming the inner part. Thus there is great difficulty in detecting any movement in the first toe.

Unfortunately amongst the mammalia there are comparatively few animals below the primates that are plantigrade. The great majority are digitigrade, walking on the phalanges with the metatarsus and tarsus raised above the ground. In the digitigrade animals a plantar response, obtained in the usual way, is not to be expected, even though the stimulus be applied over the metatarsus. This is what is found, for the guinea-pig, rabbit, fennec, and cat are digitigrade. It does not, however, necessarily follow that all plantigrade animals give a flexor plantar response, for the chipmunk is plantigrade; and the responses were so slight in the case of the mongooses that it was very difficult to be certain that the toes moved at all. There was no question of the response being extensor, but of there being any response. If there was one, it was flexor.

In the higher animals plantar reflexes were readily obtained. Corresponding with the previous observations of Collier, ${ }^{6}$ all the monkeys gave extensor plantar responses, with the exception of one foot of one of the spider monkeys, and one foot of the Bengal monkey. In the case of the former the animal was endeavouring to withdraw its foot during the observations, thus necessitating holding the leg firmly. In the case of the Bengal monkey, the feet were very cold at the time of the observation, making the response difficult to obtain. ${ }^{6}$ As will be seen from the table, the only member of the higher apes examined gave an extensor plantar response. This animal, a chimpanzee, was only 10 to 12 months old, and as chimpanzees of this age are able to walk readily if necessary - although, of course, the usual mode of progression is on the knuckles of the hands-it is not at all probable that the plantar response would change at a later period.

Thus the investigations described above point to the conclusion that the normal plantar response, if present, is of the plantar flexion type in the lower animals, whereas in the primates it is of the dorsiflexion, or extensor, variety. 


\section{III.-THE PLANTAR RESPONSE OF THE HUMAN INFANT.}

The investigations carried out upon the human infant consisted of the examination of the plantar response on a series of 101 children, all under 15 days old. It was thought that, if very young infants were examined, any hereditary relic which may pass away later might be detected, if present. The following were the results obtained :-

Table II.

\begin{tabular}{cc|c|c|c|c}
\hline Age in days & $\begin{array}{c}\text { Total No. } \\
\text { examined }\end{array}$ & $\begin{array}{c}\text { Total No. } \\
\text { giving flexor }\end{array}$ & $\begin{array}{c}\text { Total No. } \\
\text { giving extensor }\end{array}$ & $\begin{array}{c}\text { Inde- } \\
\text { terminate } \\
\text { or doubtful }\end{array}$ \\
\hline 0 to 6 (incl.) $\ldots$ & $\ldots$ & 70 & 24 & 42 & 4 \\
7 to 14 (incl.) $\ldots$ & $\ldots$ & 31 & 3 & 26 & 2 \\
\hline
\end{tabular}

In the above table the cases in which the nature of the response was doubtful have been placed in a separate column.

In order to find the percentage of infants that gave an extensor response in the whole series, it is necessary to eliminate all the doubtful cases. When this is done it will be seen that in the series of 95 thus obtained, 69.5 per cent of infants gave an extensor plantar response, 30.5 per cent a flexor. Thus in the first fortnight of life just under one-third of all infants have a flexor plantar response. The total number of 95 infants examined is sufficient for an approximate generalization, for if Poisson's rule ${ }^{19}$ for finding the possible maximum error be applied, it will be seen that, however great the series is, the percentage of infants giving a flexor plantar response could only vary between the limits of 33.05 per cent and 27.95 per cent, that is, within a range of 2.55 per cent.

If the gross figures be analyzed still further, and the percentage of infants giving flexor plantar responses during the first and then during the second week be noted, the percentage of flexor plantar responses is found to be greater during the first week than during the second. This agrees with the observations of Bersot $^{3}$, who states that in very young infants a flexor plantar response is obtained.

Table III.

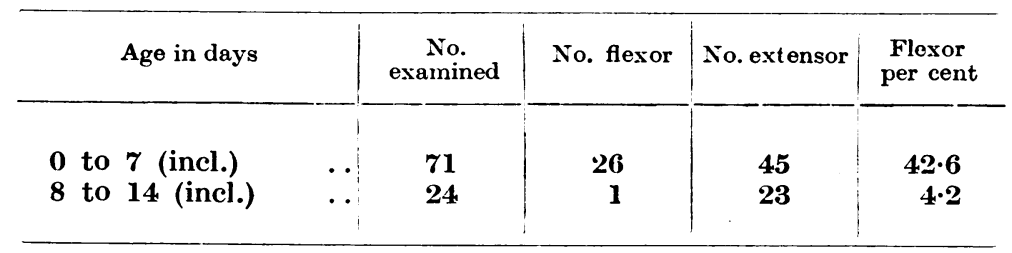


Now, in the first eight weeks after birth 92 per cent of infants give an extensor response ; in the first year 77 per cent; and in the second and third year 5 per cent. ${ }^{11}$ Cattaneo, ${ }^{5}$ however, found that only 30 per cent of infants under the age of four months gave an extensor response. From the figures of Monrad-Krohn quoted first, on the other hand, it can be presumed that during the first eight weeks of life 8 per cent of infants give a flexor response; during the first year 23 per cent; and in the second and third year 95 per cent. Therefore it appears that during the first part of life a large number of flexor plantar responses are obtained. This number becomes steadily less, and then at a later period becomes greater and greater, giving place to the permanent flexor plantar response of the adult, or rather post-infant period, (see Chart I). The chart shows the very rapid decrease in the percentage number of flexor plantar

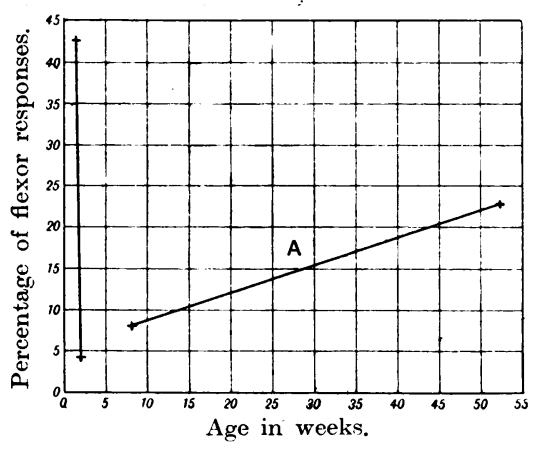

Chart I.

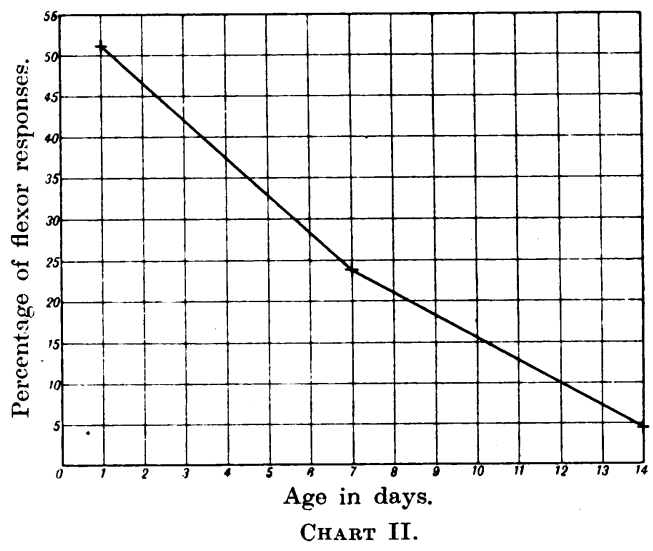

Chart II.

A =Graph based on Monrad-Krohn's figures.

responses present in the first weeks of life. The gradients of the two lines should be compared, although, of course, the graph based upon the figures given by Monrad-Krohn includes infants of one and two weeks old, as this writer gives his first percentage upon infants up to eight weeks old.

On looking still more closely into the responses present during the first two weeks of life it will be seen that the flexor plantar response occurs mainly during the first twenty-four hours of life. Thirtythree infants were examined from birth up to 24 hours old; 38 from 24 hours old to the beginning of the eighth day; and 24 from the beginning of the eighth day to the end of the fourteenth. The results are given as a graph in Chart $\boldsymbol{I I}$, which shows that there is a uniform fall in the percentage of flexor plantar responses as the infant grows older. 
In certain instances, the same infant was examined at different ages. In the majority of the infants examined, alterations in the plantar responses were not found. Some of the cases in the table below are, however, worth further consideration. Infants Nos. 1, 4, 5, and 6 show that a certain number of babies do not commence life with the the early flexor plantar response, or, as it might be termed, 'the infantile flexor response', in contradistinction to Collier's 'infantile response', ${ }^{6}$ the extensor response of the older child. 'The total series of infants examined also shows that a number of babies commence life with an extensor plantar response. Infants Nos. 2, 3, and 4

Table IV.

\begin{tabular}{|c|c|c|c|c|c|}
\hline No. & Sex & Age & Right & Left & Notes \\
\hline 1 & Male & $\begin{array}{l}\text { At birth } \\
3 \text { days }\end{array}$ & $\begin{array}{l}\mathbf{E} \\
\mathbf{E}\end{array}$ & $\begin{array}{l}\mathbf{E} \\
\mathbf{E}\end{array}$ & \\
\hline 2 & Male & At birth & Nil & Nil & $\begin{array}{l}6 \text { weeks } \\
\text { premature. }\end{array}$ \\
\hline & & $\begin{array}{l}4 \text { days } \\
5 \text { days }\end{array}$ & $\begin{array}{l}\mathbf{E} \\
\mathbf{F}\end{array}$ & $\begin{array}{l}\mathbf{E} \\
\mathbf{F}\end{array}$ & \\
\hline 3 & Malc & $\begin{array}{l}3 \text { mins. } \\
4 \text { days } \\
6 \text { days }\end{array}$ & $\begin{array}{l}\mathbf{F} \\
\mathbf{E} \\
\mathbf{E}\end{array}$ & $\begin{array}{l}\mathbf{F} \\
\mathbf{E} \\
\mathbf{E}\end{array}$ & \\
\hline 4 & Male & $\begin{array}{l}5 \text { mins. } \\
7 \text { days }\end{array}$ & $\begin{array}{l}\mathbf{E} \\
\mathbf{F}\end{array}$ & $\begin{array}{l}\mathbf{E} \\
\mathbf{F}\end{array}$ & \\
\hline 5 & Male & $\begin{array}{l}2 \text { hours } \\
11 \text { days }\end{array}$ & $\mathbf{E}$ & $\mathbf{E}$ & \\
\hline 6 & Male & $\begin{array}{l}1 \text { day } \\
2 \text { days }\end{array}$ & $\begin{array}{l}\mathbf{E} \\
\mathbf{E}\end{array}$ & $\begin{array}{l}\mathbf{E} \\
\mathbf{E}\end{array}$ & \\
\hline 7 & Male & 2 days & $\mathbf{E}$ & $\mathbf{E}$ & \\
\hline 8 & Female & 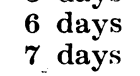 & $\mathbf{E}$ & $\begin{array}{l}\mathbf{F} \\
\mathbf{E}\end{array}$ & \\
\hline
\end{tabular}

demonstrate the variability of the plantar response. No. 2 was born six weeks prematurely, and no plantar response was obtained on either foot. This child was the only one in the whole series of 101 that gave no response, and the suggestion is either that the reflex centres in the cord and the pyramidal tracts are not functioning in a $7 \frac{1}{2}$-months foetus, or else that the peripheral nerves in connection with these centres are not functioning at this period of the child's existence. This absence of plantar response as shown by the great toe corresponds with the observations of Bersot, ${ }^{3}$ who found that in 4- to 5-month fotuses and in those of 27 to 28 weeks the big toe is generally motionless after plantar stimulation. Occasionally it moves in plantar flexion. In fotuses of 34 to 36 weeks, however, the same writer states that the response of the great toe is usually extensor, vOL. II.-NO. 8. 
although sometimes flexor. He also observes that the response in 30- to 32-weeks foetus is one of plantar flexion, being similar, he says, to that obtained immediately after birth. Unfortunately the author quoted gives neither percentages nor the total number of fotuses examined, but merely makes generalizations, based, presumably, upon his own observations.

The general condition of a premature baby at birth is another factor which suggests that the nervous system is not functioning fully, for the muscles have little or no tone, whereas in the full-time child these structures are firm. After birth, however, the reflexes must commence functioning almost at once, for within four days, in child No. 2, an cxtensor response was obtained, which became flexor on the fifth day. Evidently in this case the nervous system began to function very quickly, as if the sudden change from intra- to extrauterine life stirred this system to unusual vigour, for the adult flexor

Table V.

\begin{tabular}{|c|c|c|c|c|}
\hline \multirow{2}{*}{ No. } & \multicolumn{3}{|c|}{ 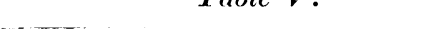 } & \multirow{2}{*}{ Left } \\
\hline & Sex & Age & Right & \\
\hline \multirow[t]{2}{*}{1} & $\mathbf{M}$ & 2 days & $? \mathbf{E}$ & $? \mathrm{E}$ \\
\hline & MI & 2 days & $\mathbf{E}$ & E \\
\hline \multirow[t]{2}{*}{2} & M & 2 hours & $\mathbf{E}$ & $\mathbf{E}$ \\
\hline & $F$ & $1 \mathrm{hr} .10 \mathrm{~min}$. & $\mathbf{F}$ & $\mathrm{E}$ \\
\hline \multirow[t]{2}{*}{3} & MI & $\frac{1}{2}$ hour & F & $\mathbf{F}$ \\
\hline & $\mathbf{F}$ & $\frac{1}{2}$ hour & $F$ & $\mathbf{F}$ \\
\hline
\end{tabular}

plantar response was present by the fifth day. No. 4 is similar to No. 2, only the child was not premature. In this case the adult flexor plantar response was not obtained until the seventh day. No. 3 is more typical than the others, for there was first a flexor plantar response, which became extensor on the fourth day and was still extensor on the sixth.

Apparently the reflexes do not alter in type at the same time in both legs in all children, for in one case of a male infant five days old the left foot gave a flexor response while the right gave an extensor.

Three pairs of twins were examined (Table $V$ ), and in each case the plantar responses were similar in both members of each pair, although in pair No. 1 there was doubt whether the response was flexor or extensor in the elder child. It is probable, however, that the response was the same in this child as in the younger member of the pair.

'The relation of sex to the plantar response was also investigated. Of 38 males up to and including 6 days old, $26 \cdot 3$ per cent gave flexor plantar responses, while of 20 from 7 to 14 days old, only 20 per cent 
gave a flexor plantar response. On the other hand, of 19 females up to and including 6 days old, 52.7 per cent gave flexor plantar responses, while in 9 from 7 to $\mathbf{1 4}$ days old inclusive, no flexor plantar responses were obtained. These figures show that in the first week of life the plantar flexor response is more common among females than among males, while the converse holds during the second week. They also show that the decrease in the number of flexor plantar responses obtained during the second week as compared with the first, as shown in Chart $I$, is largely due to the alteration of the response in females, not so much in males.

The above investigations demonstrate : (1) That there is a period consisting of the first week of life, and to a certain extent the second also, in which a flexor plantar response is often present. (2) This early flexor plantar response, or 'infantile flexor response' (I.F.R.) changes later into the normal extensor plantar response-Collier's 'infantile response'. (3) In some cases, the child commences life with an extensor plantar response, apparently omitting the I.F.R. (4) Twins apparently possess the same type of plantar response. (5) The plantar response need not necessarily change in character in both feet simultaneously. (6) Female infants obtain the extensor plantar response at an earlier period than the males.

\section{IV.-CONCLUSIONS.}

Upon consideration of the investigations described above, in association with the theories given in Part $I$ of this article, various deductions can be made.

When the phylogenetic theory of the plantar response is riewed in connection with these investigations, it is seen to be supported by a number of facts. If the theory be correct, and the extensor plantar response of infants and of corticospinal disease is really a return to the prehensile toe of our arboreal ancestors, then one would expect to find the normal plantar response extensor in character in arboreal creatures. This was the case with the great majority of animals examined, all the primates giving extensor plantar responses, although in the kinkajou and the chamæleon, both of which are arboreal creatures, the response was flexor.

Again, if the extensor reflex be really an atavistic phenomenon representing a prehensile toe, then it should be found in human infants, for the latter often use their toes for grasping purposes. ${ }^{20}$ This is what is found in the large majority of cases.

On the other hand, peoples, such as the Japanese, ${ }^{2}$ who use their great toes for prehensile purposes, might be expected to have extensor plantar responses as a normal adult condition. Also the kinkajou 
should have this type of response, for it spends most of its life in trees, and yet the response was markedly flexor. This could perhaps be explained by saying that its foot is not adapted so well to arboreal existence as is that of the primate. The same reasoning, of course, applies to the foot of the Japanese, however much the great toe is used for prehensile purposes in that race.

If the presence of a flexor plantar response is only dependent upon the integrity of the pyramidal tracts, then it might be expected that animals with an extensor plantar response would have an incomplete pyramidal system, either non-myelinated or structurally interrupted. Neither of these conditions is found, however, in the primates. If the theory be correct, therefore, it would have to be assumed that the function of the pyramidal tracts in man is different from that of the tracts in primates, and all experimental work is based upon the assumption that the functions are similar throughout the mammals.

If the theory that the character of the plantar response is dependent upon the myclination of the pyramidal tracts ${ }^{16}$ be considered with regard to human infants, certain data might be taken to support it. Thus myelination of the corticospinal paths in man occurs at the first month after birth, ${ }^{15}$ although they first make their appearance in the fifth fotal month. ${ }^{1}$ Myelination of the peripheral nerves, however, is not complete until the eighth month after birth, ${ }^{4}$ so that it is not until towards the end of the first year of extra-uterine life that structural connection between the sole of the foot and the spinal cord is complete, and this is the period when the extensor plantar response of the infant changes to that of the adult. Accordingly it might very well be said that the change from the extensor to the flexor type is correlated with the myelination of the pyramidal tracts and peripheral nerves. From a consideration of the reflexes found in the lower animals, however, the myelination of these parts of the nervous system cannot be the only condition necessary for the appearance of the adult flexor response, for myelination is present in the monkeys and yet their plantar response is extensor in type.

It has also been stated that the alteration in response from extensor to flexor occurs when the child begins to walk. ${ }^{9}$ As this takes place at about twelve months of age, ${ }^{10}$ and as the figures of MonradKrohn already quoted show that the majority of responses change at this period of the child's life, it is probably correct to say that there is an association between the two. Further, in rickets, when the child begins to walk at a late age, the extensor plantar response is retained until the infant commences walking. ${ }^{14}$ It should, however, be remembered that the weaning of the child also takes place at the end of the first year, in particular amongst the poorer classes from 
whom most statistics are obtained, since they form the bulk of hospital patients.

As for the extensor plantar response being really a part of a reflex movement of the entire limb, there is nothing in these investigations pointing to a contrary conclusion; for, in this article, the terms 'extensor' and 'flexor' are only so used with reference to the movements of the great toe, those of the various muscles not being studied, and so the responses of these structures may be of various types in the subjects examined. However, the reflex must be of value to the creature concerned, and therefore the most significant and important part of the response is the movement of the great toe, for this is the only external difference between the two types of response, however the actual reflex is brought about.

Upon consideration of the investigations described in this article, it will be seen that as the animal scale is ascended the type of plantar response varies, for the lower creatures give no response or a flexor one, the higher creatures an extensor reflex, while adult man gives a flexor plantar response. Thus there is a succession of flexor, extensor, flexor (or F.E.F.) responses as the animal scale is climbed. Now, on turning to man, it will be at once apparent that there is a similar succession of type of plantar response in the development of the average individual. In the very young infant the response is often flexor, then as the child grows older it is extensor in character, and finally this changes to flexor; thus the same succession (F.E.F.) of plantar responses occurs in man as in the animal kingdom. The stage when no plantar response is present, as in the foctus of $7 \frac{1}{2}$ months that was examined, may correspond with the stage of the amphibia and most reptilia in the animal kingdom, where no reflexes were obtained.

This similarity between the succession of the plantar responses in the animal kingdom and in man suggests that the various plantar reflexes obtained in a healthy human being are only a manifestation of the theory so well known that the phylogeny of the race is seen in the ontogeny of the individual.

The succession, F.E.F., of the plantar responses, with an absent response to begin with, corresponds to, and perhaps explains, the phenomena of total transection of the spinal cord in man. Riddoch ${ }^{12}$ found that after complete transection there is a period, known as 'spinal shock', in which no plantar response is obtainable; it lasts for one to three weeks. Then, in certain cases, a flexor plantar response is developed, lasting up to as many as forty-two days. This plantar response subsequently changes in character and becomes the weli-known pathological extensor response. If these observations of Riddoch are considered in connection with the F.E.F. succession 
of plantar responses, it will be realized that the phenomena observed after total transection of the cord are actually a repetition of the ontogenetic, and phylogenetic, history of the plantar response. On section of the pyramidal tracts, the plantar response apparently returns inmediately to its most primitive condition, i.e., to what obtains in the $7 \frac{1}{2}$-months foetus and the amphibia and reptilia, with no response at all. As the cord becomes used to the loss of connection with the higher centres of the brain, a flexor plantar response is developed, which in turn develops into the extensor plantar response. This is apparently unable to become the adult flexor plantar response without some connection with a normally functioning brain, a point to be referred to again later.

It might be argued that the early flexor plantar response obtained after transection of the cord is really the adult flexor plantar response, and that the cord automatically 'carries on' after the stage of 'spinal shock' is recovered from, as it did before the lesion occurred, and that it is only after the properties of 'carrying on' have been exhausted that the extensor plantar response appears. This, however, cannot be the case, for the temporary flexor response obtained after the 'spinal shock' is of a different nature from the normal adult response. In 1899, Collier ${ }^{6}$ showed that the adult flexor plantar response is really a part of a complex movement associated with : (1) Contraction of the tensor fasciæ femoris, sartorius, adductors and flexion of the hip ; (2) Flexion of the four outer toes; (3) Dorsiflexion of the ankle; (4) Flexion and adduction of all the toes; inversion of the foot by tibialis posticus; flexion of the knee ; (5) Contraction of calf-muscles ;

(6) Contraction of quadriceps.

Now the temporary flexor plantar response obtained after transection of the cord is unaccompanied by palpable tightening of the tendons of the inner hamstrings, or of any other muscle of the lower limb. Iater, contraction of the hamstrings occurs, even while the flexor plantar response is still present. ${ }^{12}$ But as this contraction is an integral part of the extensor plantar response, since Walshe ${ }^{18}$ has shown that this reflex never occurs without contraction of limb flexors, it is probable that the hamstring contraction occurring towards the end of the stage of temporary flexor response is really the beginning of the acquisition of the extensor plantar response.

Gordon Holmes has also shown that the temporary flexor response obtained after transection of the cord in certain cases is different from the normal reflex. ${ }^{8}$ As it is only found in a few cases, it is probably related to the fact that apparently some babies do not pass through the stage of infantile flexor response, at any rate, after birth. No doubt such people are of a more advanced type as regards the plantar response than those whose plantar responses are flexor in 
character immediately after birth, for they have passed, and left behind them, the primitive flexor plantar response which occurs far back in the pedigree of the human race.

Throughout this article the expression 'pyramidal tracts' has been used without defining clearly whether the crossed or direct tracts are those to which reference is made. By 'pyramidal tracts' is meant the crossed pyramidal tracts, for apparently the direct pyramidal tracts can have no connection with the plantar response. The direct pyramidal tracts, according to Schäfer, are only found in man and the anthropoid apes $;^{13}$ therefore, if they are correlated with the plantar response, there should be either a similarity between the normal plantar reflex of man and the anthropoids, or a dissimilarity between the responses of the latter and the monkeys. As can be seen from Table $I$, neither condition exists.

Reference has been made to the connection of the brain with the plantar response; this part of the subject will now be discussed.

In 1914, Walshe ${ }^{18}$ published some observations upon cases of complete flaccid paraplegia following cord lesions. These observations suggested that the extensor plantar response is a spinal reflex movement appearing when cerebral control is removed by impaired activity of the pyramidal tracts. Hence the character of the plantar response is dependent upon the proper functioning of the brain and upon its connection with the lower part of the spinal cord.

Other facts point in the same direction. One of these emerges from the investigations carried out by Collier, ${ }^{6}$ who found that in some children under twelve years of age the normal flexor plantar response became extensor during sleep. During this state cerebral control is presumably withdrawn from the spinal cord, while the pyramidal tracts remain healthy. Possibly the reason why the above plantar responses were only found in some children is connected with the state to which the nervous system had advanced. In those whose nervous system had reached a high degree of development the extensor plantar response would not return during sleep, for the mechanism by which the response could be brought about would be lost, the cord having progressed beyond the stage at which, at a moment's notice, it could take over the functions of the brain. An alternative reason for the presence of the extensor plantar response during sleep might be that, in the more highly developed nervous system, the higher centres in the brain might act reflexly, having progressed to such an automatic state that a flexor plantar response was given, even though the conscious brain was asleep.

The phenomena occurring after total transection of the cord in nian also suggest that the character of the plantar response is dependent upon the active functioning of the brain; when the latter 
is withdrawn, the cord is unable at once to return in all cases to the immediate primitive condition, for the cases examined by Riddoch were adults. The cord, however, even in adults, can return to a primitive condition, giving an extensor plantar response ; but it must, as it were, be re-educated first, passing through its phylogenetic history in the process.

Lastly, if the investigations deseribed in Parts II and III of this paper are viewed in the light of the theory that the character of the response is dependent primarily upon the brain, and only upon the pyramidal tracts in that they are the paths by which the brain controls the plantar reflexes, they will be seen to suggest the correctness of the theory. For, as the brain becomes more developed, the plantar response changes from the early flexor type to the extensor, and then to the flexor of the highly-developed human adult. In viewing the same F.E.F. succession of responses in the growing child, the same correlation with the development of the brain will be noticed; the mental outlook of the infant must develop enormously in the first few days after birth, and again towards the end of the first year of life when the child begins to talk. It is perhaps significant that the approximate time when speech begins should coincide with the development of the permanent flexor plantar response, for in infants before they have learnt to talk, and in anthropoid apes and monkeys, who of course are unable to talk, the extensor plantar response is the normal condition. This suggests that the type of plantar response is dependent upon the development of the brain.

Apparently the most highly developed spinal cord, that of man, is unable to produce the most advanced type of plantar response, the adult flexor plantar response, unless it is connected with that other possession of mankind alone, the highly-developed brain.

\section{SUMMARY.}

The following conclusions may be drawn from the investigations described in this article :-

1. There is a flexor plantar response of a primitive character that occurs in the lower animals, in the majority of very young human infants (the infantile flexor response), and in certain cases of total transection of the adult human cord.

2. The primitive flexor plantar response changes to an extensor response as development proceeds, either as the animal scale is ascended, or as the child grows older, or as the spinal cord re-adapts itself to its altered conditions after transection.

3. The extensor plantar response changes to a flexor plantar response in animals higher than the anthropoid apes, i.e., in man. 
Thus there is a succession of flexor, extensor, flexor, or F.E.F., responses both in the phylogeny of the race and in the ontogeny of the individual. In the case of total transection of the cord in man, the final adult flexor plantar response is not obtained.

4. The theory that the alteration of the plantar response from extensor to flexor is due to the myelination of the pyramidal tracts is apparently incorrect; more probably it is duc to the myelination of the peripheral nerves, which occurs at the eighth month of life.

5. The hypothesis that the extensor plantar response of infants and of 'spinal' man is an atavistic phenomenon dependent upon the prehensile toe of our arboreal ancestors is not shown by these investigations to be incorrect.

6. The normal adult flexor plantar response is due to the control of the brain over the lower centres of the cord, and this control is exercised only by the brain in its most highly developed form, i.e., the brain of man.

In conclusion, I must thank most sincerely all those who have so kindly helped with this investigation. In particular I wish to thank Dr. Kinnier Wilson, of King's College Hospital, for his invaluable aid; also Dr. C. F. T. East, Mr. M. Ahmad, and the Misses N. B. Daniell, L. M. Elsom, M. A. Quine, R. Leak, M. V. Saul, and A. B. Smith. I must also thank all those who so kindly allowed me to examine animals under their care, particularly Mr. R. I. Pocock, F.R.S., Superintendent of the Gardens of the Zoological Society, Regent's Park; Mr. A. Edmunds, F.R.C.S., of King's College Hospital ; and Mr. Vincent, Director of Messrs. Gamage Ltd.

Since the above was written, Dr. Burr's article in the American Journal of Diseases of Children, Vol. xxi, June, 1921, has been brought to my notice. Dr. Burr states that the plantar response may be absent up to the third month or longer in human infants. He quotes his own and Engstler's figures in support of this. ${ }^{21}$ In no infant in my series was the plantar response absent with the exception of the one case mentioned. This apparent difference in the results of the investigations may be due to the circumstance that both Burr and Engstler regard as a plantar response the movement of the toes, not of the great toe alone. Consequently, if the great toe were to move while the other toes were motionless, Burr and Engstler would presumably describe the response as absent, whereas I should describe it as present. 


\section{REFERENCES.}

1 Bailey, F., and Minler, A., Text-book of Embryology, 1912, 519.

${ }^{2} \mathrm{Bazz}$, The Bodily Characteristics of the Japanese.

${ }^{3}$ Bersot, H., Arch. Suisses Neurol. et Psygchiat., 1920, vii, 212.

${ }^{4}$ Ibid., 1921, viii, 47 .

¿Catraneo, C., 'Ueber einige Reflexe im ersten Kindesalter', Jahrb.f. Kinderh., 1902.

${ }^{6}$ Colliler, J., Brain, 1899, xxii, 71 .

7 Friedian, Jour. Nerv. and Ment. Dis., 1920, li, 146.

${ }^{8}$ Holmes, G., Goulstonian Lectures, 1915, Brit. Med. Jour., 1915, ii, 769.

${ }^{9}$ Hetchisos, R., Lectures on Diseases of Children, 1918, 12.

${ }^{10}$ Ibid., 14.

11 Monrad-Krohn, G., Clinical Examination of the Nervous System, 1921, 71.

${ }^{12}$ Rindoch, G., Brain, 1917, xl, 264.

${ }^{13}$ Schärer, E., Esscntials of II istology, 1916, 424.

14 Salovovsox, J. W., Brain, 1921, xliii, 369.

15 Staring, E., Principles of IIuman Physiology, 1915, 320.

16 Tersier, A., and Strwart, G., Text-book of Nervous Diseleses, 1910, 45.

17 van Wokr kon, Revue neurol., 1912, ii, 285.

18 Walshe, F., Brain, 1914, xxxvii, 269.

${ }^{19}$ Whithelegie, A., and Newmas, G., IIygiene and Public ILealth, 1919, 7.58.

20 Windenshem, R., The Structure of Man (Trans. by Bernard), 189., 46.

21 Evgstuk, G., Wien. klin Woch., 190.5, June 1. 